\title{
Surgical management of clinoidal meningiomas: 10 cases analysis
}

\author{
Shamsul Alam¹, Bipin Kumar Chaurasia1, Narendra Shalike1, Abu Naim Wakil Uddin', Dhiman Chowdhury, \\ Akhlaque Hossain Khan ${ }^{1}$, Ayub Ansari'1, Kanak Kanti Barua', Mashiur Rahman Majumder ${ }^{2}$ \\ 'Department of Neurosurgery, Bangabandhu Sheikh Mujib Medical University, Dhaka 1000, Bangladesh. \\ ${ }^{2}$ Department of Neurosurgery, Comilla Medical College, Comilla 3500, Bangladesh.
}

Correspondence to: Dr. Shamsul Alam, Department of Neurosurgery, Bangabandhu Sheikh Mujib Medical University, Shahbag, Dhaka 1000, Bangladesh. E-mail: dr_shamsul@hotmail.com

How to cite this article: Alam S, Chaurasia BK, Shalike N, Wakil Uddin AN, Chowdhury D, Khan AH, Ansari A, Barua KK, Majumder MR. Surgical management of clinoidal meningiomas: 10 cases analysis. Neuroimmuno/ Neuroinflammation 2018;5:21. http://dx.doi.org/10.20517/2347-8659.2017.64

Received: 20 Dec 2017 First Decision: 26 Feb 2018 Revised: 30 Mar 2018 Accepted: 12 Apr 2018 Published: 24 May 2018

Science Editor: Athanassios P. Kyritsis Copy Editor: Guang-Zhe Zhu Production Editor: Huan-Liang Wu

\section{ABSTRACT}

Aim: The purpose of this article is to advocate standard skull base technique for removing the clinoidal meningioma and to delineate the technique's advantages that aid in achieving an improved extent of tumor resection and enhancing the patients' overall outcome, specially their visual outcome.

Methods: A retrospective analysis was performed on 10 consecutive patients with clinoidal meningiomas who underwent surgical resection at the Bangabandhu Sheikh Mujib Medical University and other private clinics between May 2013 and July 2016. A standard pterional craniotomy technique consisting of extradural anterior clinoidectomy, coupled with optic canal unroofing and optic nerve sheath opening was used in all patients. All patients had thorough preoperative and postoperative ophthalmological evaluations. The follow-up period ranged from 6 to 42 months.

Results: Total resection was achieved in $5(50.0 \%)$ of the 10 patients in this series. The majority of the patients with preoperative visual impairment experienced significant visual improvement 7 of 10 patients; 70.0\%).

Conclusion: In the majority of patients with clinoidal meningiomas, total resection may be achieved with minimal complications. For large tumors encasing the optic nerve and internal carotid artery, or for those tumors causing preoperative visual impairment, use of the cranial base technique delineated in this study may lead to significant improvement in the patients' visual and overall outcomes.

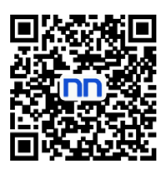


Keywords: Clinoidal meningiomas, pterional craniotomy, extradural anterior clinoidectomy

\section{INTRODUCTION}

Anterior clinoidal meningiomas arise from the meningeal covering of the anterior clinoid process. In the classical neurosurgical literature, anterior clinoidal meningiomas have not been separated from medial sphenoid wing or inner sphenoid wing meningiomas ${ }^{[1,2]}$. However, accumulating anatomical knowledge and clinical experience has shown that anterior clinoidal meningiomas have unique anatomical and clinical characteristics that puts them apart from meningiomas of the medial sphenoid wing ${ }^{[2,3]}$. Therefore anterior clinoidal meningiomas should be considered a separate clinical entity ${ }^{[2-4]}$.

Visual loss is the very common presenting symptom in these tumors ${ }^{[5]}$. The characteristic onset usually occurs with unilateral failure of vision loss associated with primary optic atrophy ${ }^{[5,6]}$. In some patients, loss of vision may extend to the uninvolved eye ${ }^{[7]}$. Visual field defects in the form of concentric narrowing of the visual field, central scotoma, and temporal hemianopsia can be seen in patients; however, the extent depends on the degree of the involvement of the chiasm and the optic nerves ${ }^{[6,8]}$. Headache is another most common symptom in these tumors, generally over the orbital or retroorbital field ${ }^{[9]}$. Although the visual problems are the major cause of presenting symptoms in anterior clinoidal meningiomas $(45.3 \%, 53.3 \%$, 58\% in some series) ${ }^{[9]}$, this rate is not as high as in other meningiomas located in the neighboring region such as tuberculum sellae meningiomas (75.9\%-100.0\%). The growth potential of the latter tumors may result in early impingement on the optic apparatus. However, for the anterior clinoidal meningiomas, this is true only for Al-Mefty group III tumors that encroach on the optic nerve at the optic foramen ${ }^{[10]}$.

Several classification schemes have been proposed as methods for predicting surgical outcome. Al-Mefty' classification of clinoidal meningiomas is based on advances in microsurgical anatomy and has been widely accepted $^{[11,12]}$. This scheme considers the origin of the tumor and its invasion pattern in the region of the clinoid process as indicators of resectability. It differentiates among Group I, lower clinoidal meningiomas (no arachnoidal dissection plane between the internal carotid artery (ICA) and tumor); Group II, distal or lateral clinoidal meningiomas (which do have an arachnoidal plane between ICA and tumor) and Group III, meningiomas that originate at the optic foramen. In Group III tumors, the arachnoidal membrane is present between the ICA and the tumor but may be absent between the optic nerve and the tumor [Figure 1$]^{[12]}$.

Because anterior clinoidal meningiomas tend to grow upward, true invasion of the cavernous sinus is very rare. The current literature on anterior clinoidal meningiomas documents a very wide range of cavernous sinus invasion rates, ranging from 0 to $44.1 \%$. We believe that this variability is, in part, a reflection of the lack of objective and universal nomenclature among authors. This problem has led to some medial sphenoid wing meningiomas being analyzed as part of the clinoidal group ${ }^{[13]}$.

Based on the new classification, the coronal diameter of the tumor is combined with the classical AlMefty group designation. Each tumor was graded (typed) with a numerical number denoting the Al-Mefty grouping and a capital letter representing the tumor size on coronal section ${ }^{[14]}$. A tumor was defined as type A if it was measured less than $2 \mathrm{~cm}$, type B if it was 2 to $4 \mathrm{~cm}$, and type $C$ (giant) if it was greater than $4 \mathrm{~cm}$. These designations were applied to each group in the current Al-Mefty classification [Figure 1] ${ }^{[12]}$.

Many surgeons used various skull-base approaches with or without intra- or extradural removal of anterior clinoid for resecting these challenging tumors. The recent articles by Al-Mefty ${ }^{[14]}$, Lee et al.$^{[15,16]}$ described a cranial base technique that is a modification of the original "Dolenc approach" and involves extradural clinoidectomy, removal of the roof of the optic canal, and opening of the optic nerve sheath. Mathiesen et al. ${ }^{[17]}$ 


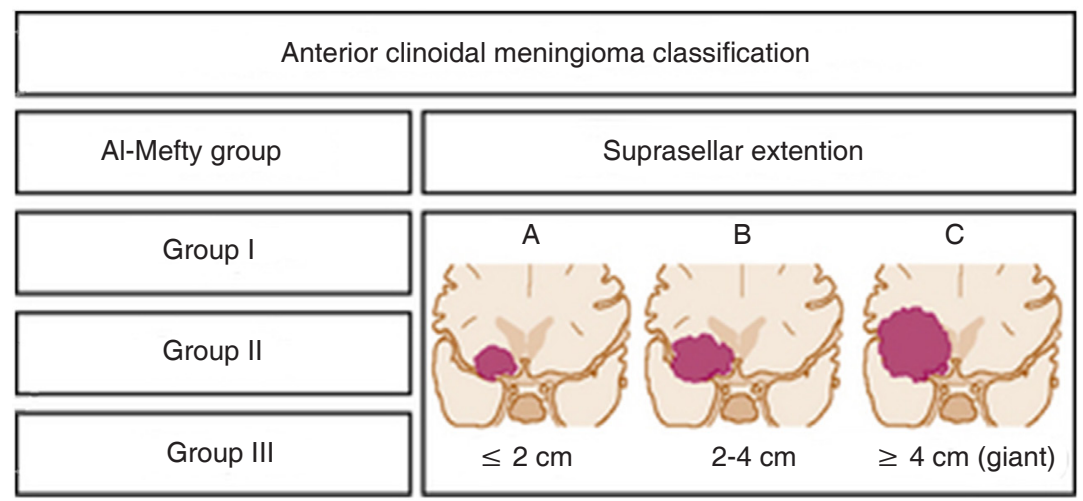

Figure 1. Classification system for anterior clinoidal meningiomas: the coronal size of the tumor is categorized and each category represents a subdivision of each Al-Mefty group classification (cited with permission from https://clinicalgate.com/anterior-clinoidalmeningiomas/)

also stated that, to achieve or ensure better visual function, it is best to use an extradural approach with drilling of the anterior clinoid and removal of the roof of the optic canal before any intradural steps are performed.

\section{METHODS}

All patients were investigated preoperatively with coronal computed tomography (CT) and triplanar contrast-enhanced magnetic resonance imaging of brain. Digital subtraction angiography and CT angiogram were done in some cases to delineate the anatomy of the cerebral circulation, encasement of major vessels, arterial displacement, and blood supply. Visual testing that included determination of visual acuity, visual field and fundal photography was performed preoperatively and postoperatively in all cases. Al-Mefty ${ }^{[14]}$ and Lee et al. ${ }^{[18]}$ exclusively used the orbitocranial approach and stated its advantages as: the shortest distance to tumor, suitability for surgical attack via multiple routes, and early interception of the tumor's blood supply through the sphenoid ridge.

\section{Surgical technique}

The patients were positioned in supine with head turned contraleteral 30-degree angle, fixed with three pin head fixators. Standard pterional craniotomy was done in all cases. Following pterional craniotomy extradural anterior clinoidectomy was done either by high speed drill or bone forceps [Figure 2].

Extradural identification of optic nerve and clinoidal carotid artery was done. Curvilinear durotomy over the tumor was done which was extended to the optic nerve or carotid artery in a $\mathrm{T}$ fashion to enhance close proximity of optic nerve, carotid artery and tumor. Gentle debulking of the tumor following cautery of tumor's dural attachment was done. Peripheral dissecting of tumor from the brain parenchyma was done following bipolar cautery of the feeding vessels to end from brain. Finally, delicate dissection from middle cerebral artery (MCA), anterior cerebral artery (ACA), posterior communicating artery (PCOM), carotid bifurcation area, optic nerve and chiasm was done. Dural closure was done with or without graft, bone and wound was closed in multiple layers.

\section{RESULTS}

We operated upon 10 cases of clinoidal meningioma. Among them 3 were male and 7 were female [Table 1].

The ages of patients ranged from 21-60 years. The mean age was $45 \pm 13.12$ years [Table 2]. 
Table 1. The distribution of patients by gender $(n=10)$

\begin{tabular}{lcc}
\hline Gender & No. of patients & Percentage \\
\hline Male & 3 & $30.0 \%$ \\
Female & 7 & $70.0 \%$ \\
Total & 10 & $100.0 \%$ \\
\hline
\end{tabular}

Table 2. The age of the patients $(n=10)$

\begin{tabular}{lcc}
\hline Age group (in years) & No. of patients & Percentage \\
\hline $21-30$ & 1 & $10.0 \%$ \\
$31-40$ & 1 & $10.0 \%$ \\
$41-50$ & 7 & $70.0 \%$ \\
$51-60$ & 1 & $10.0 \%$ \\
Total & 10 & $100.0 \%$ \\
Mean age & $45 \pm 13.12$ years & \\
\hline
\end{tabular}

Table 3. The extent of tumor removal $(n=10)$

\begin{tabular}{lcc}
\hline Extent of tumor removal & No. of patient & Percentage \\
\hline Gross total & 5 & $50.0 \%$ \\
Near total & 5 & $50.0 \%$ \\
Total & 10 & $100.0 \%$ \\
\hline
\end{tabular}

Table 4. Complications $(n=10)$

\begin{tabular}{lcc}
\hline Name of complication & No. of patients & Percentage \\
\hline Hematoma & 1 & $10.0 \%$ \\
Internal carotid artery injured & 1 & $10.0 \%$ \\
Recurrence & 1 & $10.0 \%$ \\
No complication & 7 & $70.0 \%$ \\
Total & 10 & $100.0 \%$ \\
\hline
\end{tabular}

Table 5. Visual outcome $(n=10)$

\begin{tabular}{lcc}
\hline Functional outcome & No. of patients & Percentage \\
\hline Improved & 7 & $70.0 \%$ \\
Static & 2 & $20.0 \%$ \\
Deteriorated & 1 & $10.0 \%$ \\
Total & 10 & $100.0 \%$ \\
\hline
\end{tabular}

Gross total removal was achieved in 5 (50.0\%) cases [Figures 3 and 4], and near total in 5 cases (50.0\%) [Table 3].

In our study most of the patients had limited complications. Only one patient had complicated by hematoma and another, patient had ICA injury [Table 4].

In our series, we found visual improvement in 7 cases (70.0\%) [Figures 5 and 6], static in 2 cases (20.0\%), and deterioration in 1 case $(10.0 \%)$ [Table 5].

Papilledema also improved significantly after removal of tumors as shown in Figures 7 and 8.

The profile of the patients with clinoidal meningioma is shown in Table 6.

\section{DISCUSSION}

The traditional approach for the resection of anterior clinoidal meningiomas is the pterional intradural 


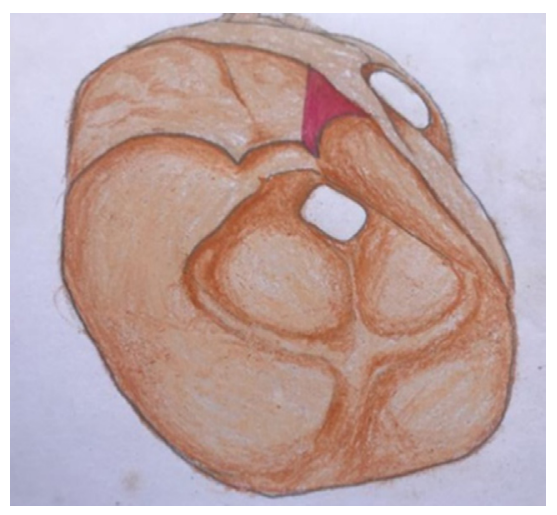

Figure 2. Following craniotomy shows removal of anterior clinoid process and unroofing of optic foramen
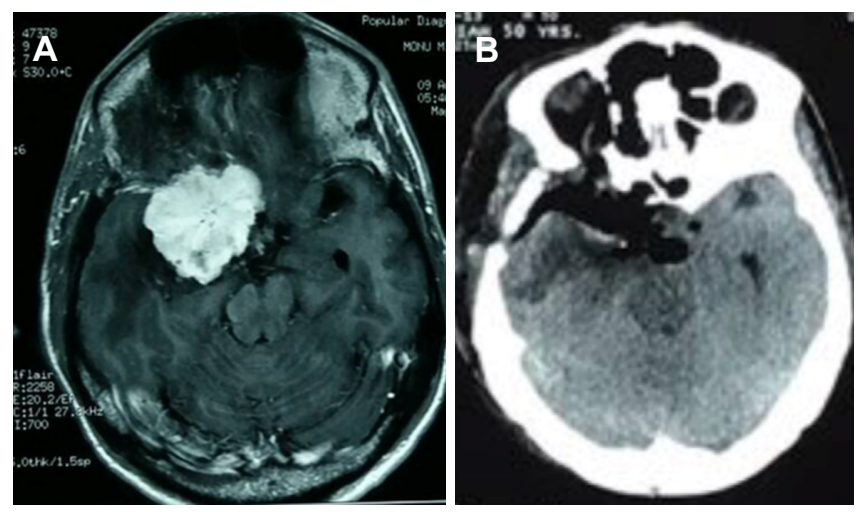

Figure 3. (A) Preoperative axial contrast magnetic resonance imaging of brain shows homogenously brilliant contrast enhancing benign tumor; (B) postoperative axial contrast computed tomography scan of brain shows complete removal of the tumor

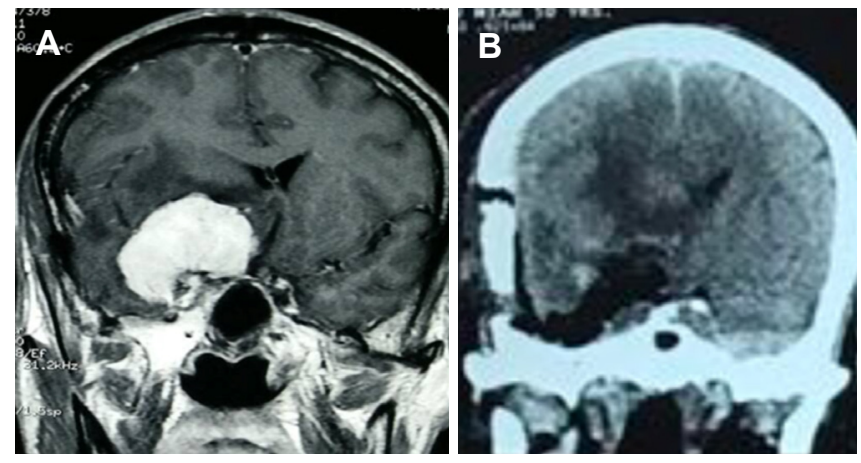

Figure 4. (A) Preoperative coronal contrast magnetic resonance imaging of brain shows homogenously brilliant contrast enhancing tumor; (B) postoperative computed tomography scan shows removal of anterior clinoid process with complete removal of the tumor

transsylvian approach, which begins with splitting the sylvian fissure, releasing cerebrospinal fluid, and debulking the tumor, and then proceeding with peripheral tumor dissection from neurovascular structures $^{[19-21]}$. In this series, we present our experience using the pterional craniotomy with extradural drilling of anterior clionoid process. The surgical challenges are associated with these giant tumors from their size, difficult location, as well as the dissection, and preservation of the critical neurovascular structures like the cavernous sinus, cranial nerves, ICA, ACA, MCA and anterior choroidal artery that they inevitably involve or encase ${ }^{[22-24]}$. These challenges are increased by tensed brain, secondary edema, and tumor mass effect ${ }^{[18,25]}$. 
Table 6. Profile of the patients with clinoidal meningioma

\begin{tabular}{|c|c|c|c|c|c|c|c|}
\hline SI. No. & $\begin{array}{l}\text { Age (years)/ } \\
\text { gender }\end{array}$ & Symptoms & $\begin{array}{l}\text { Size of } \\
\text { tumor } \\
\left(\mathrm{cm}^{3}\right)\end{array}$ & $\begin{array}{l}\text { Extent } \\
\text { of tumor } \\
\text { removal }\end{array}$ & Name of operation & Complication & Visual outcome \\
\hline 1 & $50 / \mathrm{F}$ & Headache & $6^{*} 6^{*} 6$ & Gross total & $\begin{array}{l}\text { Pterional craniotomy and } \\
\text { anterior clinoidectomy }\end{array}$ & Hematoma & Static \\
\hline 2 & $45 / F$ & Headache & $8 * 6 \star 5$ & Gross total & $\begin{array}{l}\text { Pterional craniotomy and } \\
\text { anterior clinoidectomy }\end{array}$ & $\begin{array}{l}\text { Internal carotid } \\
\text { artery injured, 3rd } \\
\text { nerve palsy }\end{array}$ & Deteriorated \\
\hline 3 & $50 / F$ & Headache & $6 * 6 * 5$ & Gross total & $\begin{array}{l}\text { Pterional craniotomy and } \\
\text { anterior clinoidectomy }\end{array}$ & Nil & Improved \\
\hline 4 & $25 / F$ & Lt eye blind & $6 \star 5 \star 5$ & Near total & $\begin{array}{l}\text { Pterional craniotomy and } \\
\text { anterior clinoidectomy }\end{array}$ & $\mathrm{Nil}$ & Improved \\
\hline 5 & $58 / M$ & Headache & $5 \star 4 \star 5$ & Near total & $\begin{array}{l}\text { Pterional craniotomy and } \\
\text { anterior clinoidectomy }\end{array}$ & Nil & Improved \\
\hline 6 & $36 / \mathrm{F}$ & Headache & $5 \star 4 * 5$ & Near total & $\begin{array}{l}\text { Pterional craniotomy and } \\
\text { anterior clinoidectomy }\end{array}$ & $\mathrm{Nil}$ & Improved \\
\hline 7 & $42 / F$ & Headache & $4 \star 5 \star 4$ & Near total & $\begin{array}{l}\text { Pterional craniotomy and } \\
\text { anterior clinoidectomy }\end{array}$ & Nil & Improved \\
\hline 8 & $45 / F$ & Headache & $4 \star 5 \star 5$ & Gross total & $\begin{array}{l}\text { Pterional craniotomy and } \\
\text { anterior clinoidectomy }\end{array}$ & Recurrence & Static \\
\hline 9 & $45 / M$ & Headache & $6 * 5 * 4$ & Gross total & $\begin{array}{l}\text { Pterional craniotomy and } \\
\text { anterior clinoidectomy }\end{array}$ & Nil & Improved \\
\hline 10 & $47 / M$ & Headache & $6 \star 5 \star 4$ & Near total & $\begin{array}{l}\text { Pterional craniotomy and } \\
\text { anterior clinoidectomy }\end{array}$ & Nil & Improved \\
\hline
\end{tabular}

The concept of an extradural approach to skull base tumors is not new. After the initial work of Dolenc ${ }^{[11]}$, the technique he introduced as an approach to the cavernous sinus evolved in the hands of other surgeons for removal of medial sphenoid wing/clinoidal meningiomas ${ }^{[26]}$.

There are 2 main challenges in the safe removal of giant tumors: (1) how to safely locate the important arteries and the optic apparatus inside these giant tumors, and (2) how to avoid damage to tensed brain during approach, dissection, and tumor removal ${ }^{[27]}$.

We presumed that the best way to avoid damaging the ICA and optic nerve was to locate and dissect them in areas in which the anatomy remains relatively normal, with minimal distortion from the tumor. Extradural clinoidectomy solves this problem ${ }^{[28,29]}$.

The extradural skull base approach that was used in our patients is similar to the technique reported by Lee et al ${ }^{[18]}$ with some modifications. They reported on 15 patients with somewhat smaller anterior clinoidal meningiomas (mean diameter $3.7 \mathrm{~cm}$ ), including 8 patients presenting with preoperative visual deficits. After surgery, vision improved in $75 \%$ cases. This good result could be related to their extradural approach and early optic nerve decompression.

In our series, we achieved visual improvement in 7 cases (70.0\%), static in 2 cases (20.0\%) and deterioration in 1 case (10.0\%).

In another study, 20 patients with preoperative visual deficits due to giant medial sphenoid wing meningiomas, Behari et al. ${ }^{[5]}$ attained visual improvement in 3 patients and stable visual function in 11; 5 patients experienced deterioration of vision in the ipsilateral eye at a mean of 17.6-month follow-up. The majority of patients in the series of Behari et al. ${ }^{[5]}$ had stable vision after surgery, while in our experience most patients' vision improved. The team of Behari et al. ${ }^{[5]}$ performed early extradural unroofing of the optic canal and optic nerve decompression in only $15.8 \%$ of their patients, whereas we used this technique in all cases.

In a series of 35 patients with medial sphenoid wing meningiomas (mean diameter $4.5 \mathrm{~cm}$ ), Russell and 

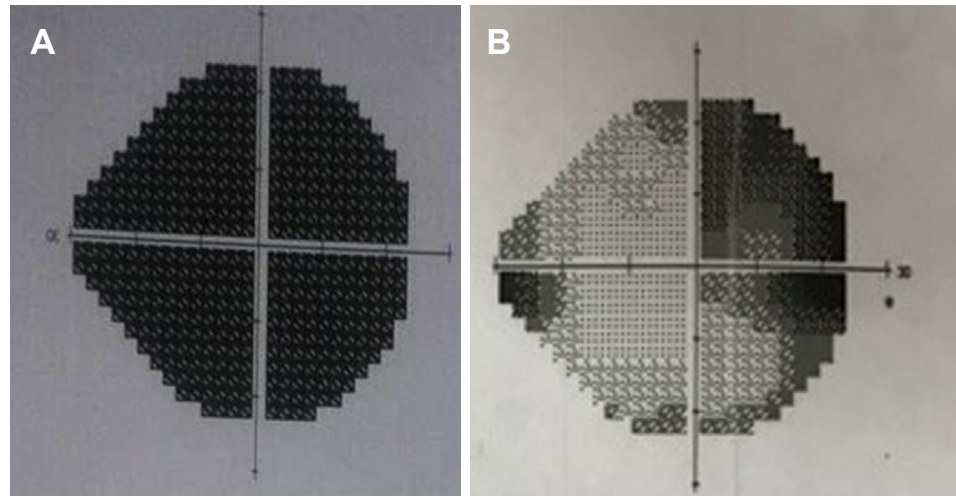

Figure 5. Humphrey visual field test. (A) Preoperative VF (right eye) with total blindness; (B) postoperative VF (right eye) with significant visual improvement
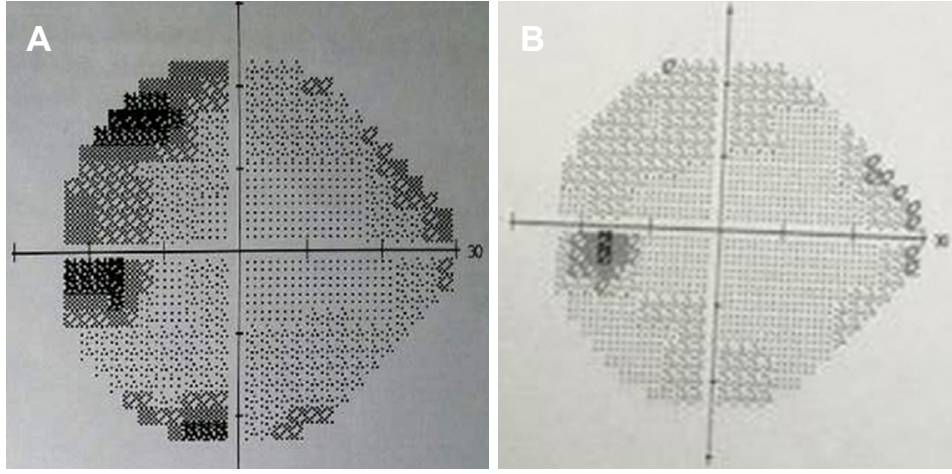

Figure 6. Humphrey visual field test. (A) Preoperative VF (left eye) with upper temporal field; (B) postoperative VF (left eye) with significant visual improvement defect
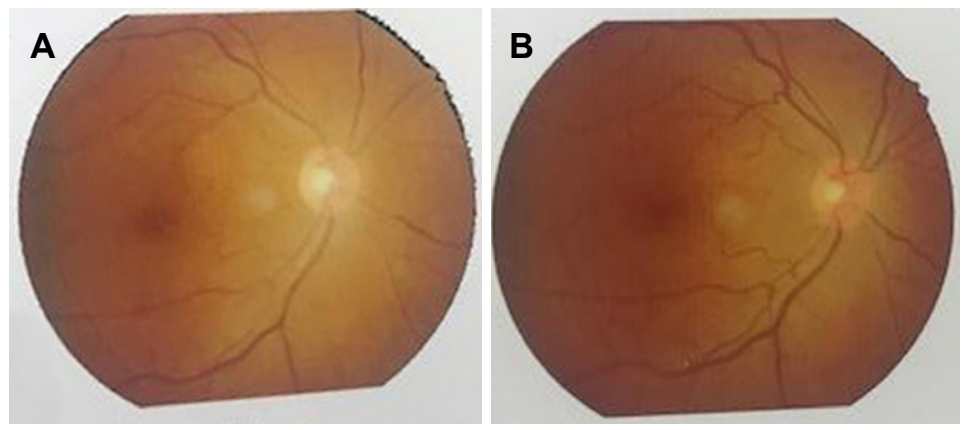

Figure 7. (A) Preoperative fundal photography (right eye) with primary optic atrophy; (B) postoperative fundal photography (right eye) with slight improvement

Benjamin $^{[30]}$ reported visual improvement in $73 \%$, stable vision in $20 \%$, and deterioration in $7 \%$ of patients who had visual loss before surgery. Pamir et al. ${ }^{[31]}$ also reported improvements in visual function in the majority of 43 patients with anterior clinoidal meningiomas with a mean tumor diameter of $3.35 \mathrm{~cm}$, including 16 patients with tumors larger than $4 \mathrm{~cm}$ in diameter. Among 26 patients who had preoperative visual deficits, $84.6 \%$ improved and $15.4 \%$ remained stable. The Russell and Pamir teams used an intradural approach. In our series, there were no deaths, in comparison with 5\%-15.4\% mortality in some recent series. Tomasello et al. ${ }^{[22]}$, whose patients had a mean tumor diameter of $5.7 \mathrm{~cm}$ and of whom $77 \%$ underwent 

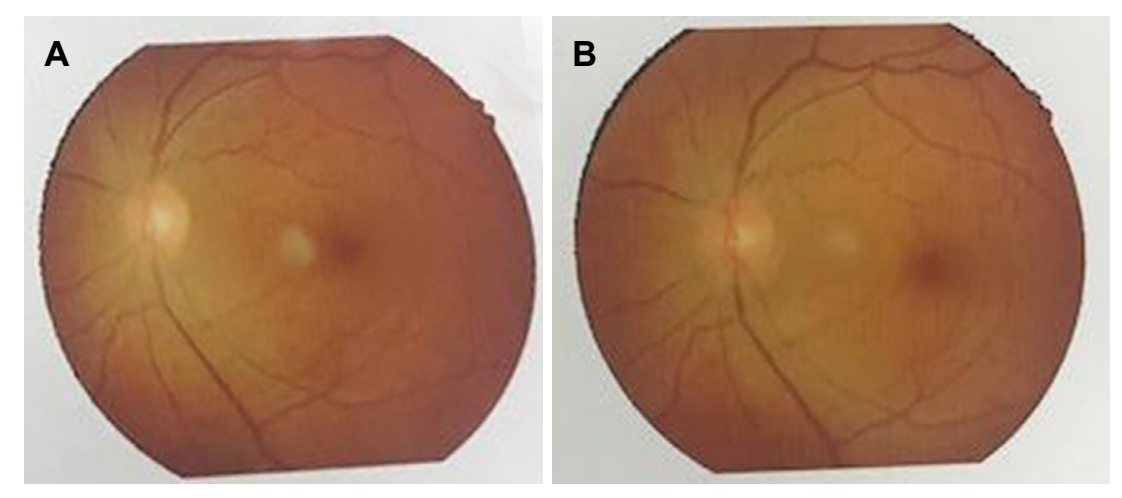

Figure 8. (A) Preoperative fundal photography (left eye) with normal findings; (B) postoperative fundal photography (left eye) with static findings

gross total resection, reported the highest mortality rate in patients treated via the conventional pterional intradural transsylvian approach. Behari et al. ${ }^{[5]}$ reported $5 \%$ mortality.

In our series, 3 patients (13.6\%) had postoperative hemiparesis. In 1 patient, the hemiparesis was caused by intracranial hematoma due to intraoperative hematoma. In other 2 patients, the deficit was most likely due to manipulation of perforating vessels encased by the tumor. Goel et al. ${ }^{[12]}$ reported postoperative hemiplegia in $6.6 \%$ of patients. Behari et al. ${ }^{[5]}$ reported $10 \%$ temporary and $5 \%$ permanent hemiparesis, and Tomasello et al. ${ }^{[2]}$ reported $7.6 \%$ hemiparesis. The encasement of small perforating vessels in clinoidal/medial sphenoid wing meningiomas is a serious problem. Injury to small perforating arteries during tumor resection is a known cause of neurological deterioration, even when the large parent vessels are well preserved ${ }^{[32,33]}$.

In conclusion, giant anterior clinoidal meningiomas are very challenging tumors. We prefer an extradural skull base approach to the tumor, including extradural unroofing of the optic canal, extradural clinoidectomy, early optic nerve decompression, and early identification and control of the clinoidal carotid artery followed by removal of the remaining tumor. This technique has provided a good extent of resection, as well as a good visual and clinical outcome.

\section{DECLARATIONS}

\section{Authors' contributions}

Conception, diagnosis and design, radiology diagnosis and final approval of manuscript: Alam S, Chaurasia BK

Manuscript preparation: Alam S, Wakil Uddin AN, Majumder MR, Shalike N, Chowdhury D

Literature search: Wakil Uddin AN, Majumder MR, Shalike N, Chaurasia BK, Khan AH

Technical revision, manuscript editing and revision: Alam S, Shalike N, Ansari A, Barua KK

\section{Data source and availability}

The data can be obtained from the computer database of Department of Neurosurgery, Bangabandhu Sheikh Mujib Medical University, Shahbagh, Dhaka-1000, Bangladesh, but it cannot be explored online.

\section{Financial support and sponsorship}

This research did not receive any specific grant from funding agencies in the public, commercial, or not-forprofit sectors.

\section{Conflicts of interest}

There are no conflicts of interest. 


\section{Patient consent}

Patients' consent was obtained from the patients.

\section{Ethics approval}

Our research proposal has been reviewed and approved by the Institutional Review Board (I.R.B.), Bangabandhu Sheikh Mujib Medical University in its 106th meeting held on 15 May 2013. Number of ethics approval is No. BSMMU/2013/2334.

\section{Copyright}

(c) The Author(s) 2018.

\section{REFERENCES}

1. Abdel Aziz KM, Froelich SC, Dagnew E, Jean W, Breneman JC, Zuccarello M, van Loveren HR, Tew JM. Large sphenoid wing meningiomas involving the cavernous sinus: conservative surgical strategies for better functional outcomes. Neurosurgery 2004;54:1375-84.

2. Jennett B, Bond M. Assessment of outcome after severe brain damage: a practical scale. Lancet 1975;305:480-4.

3. Nanda A, Konar SK, Maiti TK, Bir SC, Guthikonda B. Stratification of predictive factors to assess resectability and surgical outcome in clinoidal meningioma. Clin Neurol Neurosurg 2016;142:31-7.

4. Igressa A, Pechlivanis I, Weber F, Mahvash M, Ayyad A, Boutarbouch M, Charalampaki P. Endoscope-assisted keyhole surgery via an eyebrow incision for removal of large meningiomas of the anterior and middle cranial fossa. Clin Neurol Neurosurg 2015;129:27-33.

5. Behari S, Giri PJ, Shukla D, Jain VK, Banerji D. Surgical strategies for giant medial sphenoid wing meningiomas: a new scoring system for predicting extent of resection. Acta Neurochir 2008;150:865.

6. Coscarella E, Başkaya MK, Morcos JJ. An alternative extradural exposure to the anterior clinoid process: the superior orbital fissure as a surgical corridor. Neurosurgery 2003;53:162-7.

7. Balasingam V, Noguchi A, McMenomey SO, Delashaw JB. Modified osteoplastic orbitozygomatic craniotomy. J Neurosurg 2005;102:9404.

8. Cushing H, Eisenhardt L. Suprasellar meningiomas. In Meningiomas: their classification, regional behaviour, life history, and surgical end results. Iowa City: Hafner; 1938. p. 224-49.

9. Day JD. Cranial base surgical techniques for large sphenocavernous meningiomas. Neurosurgery 2000;46:754-60.

10. De Jesús O, Toledo MM. Surgical management of meningioma en plaque of the sphenoid ridge. Surg Neurol 2001;55:265-9.

11. Dolenc V. Direct microsurgical repair of intracavernous vascular lesions. J Neurosurg 1983;58:824-31.

12. Goel A, Gupta S, Desai K. New grading system to predict resectability of anterior clinoid meningiomas. Neurol Medico Chirurgica 2000;40:610-7.

13. Iwai Y, Yamanaka K, Ishiguro T. Gamma knife radiosurgery for the treatment of cavernous sinus meningiomas. Neurosurgery 2003;52:51724.

14. Al-Mefty O. Clinoidal meningiomas. J Neurosurg 1990;73:840-9.

15. Lee JH, Jeun SS, Evans J, Kosmorsky G. Surgical management of clinoidal meningiomas. Neurosurgery 2001;48:1012-21.

16. Lee JH, Sade B, Park BJ. A surgical technique for the removal of clinoidal meningiomas. Op Neurosurg 2006;59:ONS-108.

17. Mathiesen T, Lindquist C, Kihlström L, Karlsson B. Recurrence of cranial base meningiomas. Neurosurgery 1996;39:2-9.

18. Lee JY, Niranjan A, McInerney J, Kondziolka D, Flickinger JC, Lunsford LD. Stereotactic radiosurgery providing long-term tumor control of cavernous sinus meningiomas. J Neurosurg 2002;97:65-72.

19. Sekhar LN, Patel S, Cusimano M, Wright DC, Sen CN, Bank WO. Surgical treatment of meningiomas involving the cavernous sinus: evolving ideas based on a ten year experience. In Modern Neurosurgery of Meningiomas and Pituitary Adenomas. Vienna: Springer; 1996. p. 58-62.

20. Simpson D. The recurrence of intracranial meningiomas after surgical treatment. J Neurol Neurosurg Psychiatr 1957;20:22.

21. Moscovici S, Fraifeld S, Cohen JE, Dotan S, Elchalal U, Shoshan Y, Spektor S. Parasellar meningiomas in pregnancy: surgical results and visual outcomes. World neurosurg 2014;82:e503-12.

22. Tomasello F, De Divitiis O, Angileri FF, Salpietro FM, d'Avella D. Large sphenocavernous meningiomas: is there still a role for the intradural approach via the pterional-transsylvian route? Acta Neurochir 2003;145:273-82.

23. van Loveren HR, Keller JT, El-Kalliny M, Scodary DJ, Tew JM. The Dolenc technique for cavernous sinus exploration (cadaveric prosection) Technical note. J Neurosurg 1991;74:837-44.

24. Yaşargil MG. Microneurosurgery. Stuttgart: Thieme; 1996. p. 143.

25. Lemole GM, Henn JS, Zabramski JM, Spetzler RF. Modifications to the orbitozygomatic approach. J Neurosurg 2003;99:924-30.

26. Margalit NS, Lesser JB, Moche J, Sen C. Meningiomas involving the optic nerve: technical aspects and outcomes for a series of 50 patients. Neurosurgery 2003;53:523-33.

27. Nakamura M, Roser F, Jacobs C, Vorkapic P, Samii M. Medial sphenoid wing meningiomas: clinical outcome and recurrence rate. Neurosurgery 2006;58:626-39.

28. Noguchi A, Balasingam V, Shiokawa Y, McMenomey SO, Delashaw JB. Extradural anterior clinoidectomy. J Neurosurg 2005;102:945-50.

29. Khan OH, Anand VK, Schwartz TH. Endoscopic endonasal resection of skull base meningiomas: the significance of a "cortical cuff' and brain edema compared with careful case selection and surgical experience in predicting morbidity and extent of resection. Neurosurg Focus 2014;37:E7. 
30. Russell SM, Benjamin V. Medial sphenoid ridge meningiomas: classification, microsurgical anatomy, operative nuances, and long-term surgical outcome in 35 consecutive patients. Op Neurosurg 2008;62:ONS38-50.

31. Pamir MN, Belirgen M, Özduman K, Kılıç T, Özek M. Anterior clinoidal meningiomas: analysis of 43 consecutive surgically treated cases. Acta Neurochir 2008;150:625.

32. Risi P, Uske A, Tribolet ND. Meningiomas involving the anterior clinoid process. Br J Neurosurg 1994;8:295-305.

33. Roser F, Nakamura M, Jacobs C, Vorkapic P, Samii M. Sphenoid wing meningiomas with osseous involvement. World Neurosurg 2005;64:37-43. 